\title{
Exploring the Post-graduation Benefits of High-Impact Practices in Engi- neering: Implications for Retention and Advancement in Industry
}

\section{Trevion S. Henderson, University of Michigan}

Trevion Henderson is a doctoral student in the Center for Higher and Postsecondary Education (CSHPE) at the University of Michigan. He recently earned his master's degree in Higher Education and Student Affairs at The Ohio State University while serving as a graduate research associate with the Center for Higher Education Enterprise. Trevion also hold's a Bachelor's degree in Computer Science and Engineering from The Ohio State University, where he served as a research assistant in the College of Education and Human Ecology Center for Inclusion, Diversity, and Academic Success.

Trevion's research interests center on three foci in Engineering Education: pedagogical strategies, practices and policies that broaden minority participation, and curricular design for meeting workforce and industry needs. 


\title{
Exploring the Post-graduation Benefits of High Impact Practices in Engineering
}

\begin{abstract}
Though the United States has educated enough students in science, technology, engineering, and mathematics (STEM) fields, thousands of jobs in industry remain vacant each year. Attrition in engineering industry is a persistent problem, threatening national goals related to technological advancement and global competitiveness. As a result, educational institutions are asked to consider practices that ensure both academic success in college, as well as post-graduation outcomes in the workforce. Using survey data from a National Science Foundation funded study, titled Project to Production: Conditions and Processes for Educating the Engineer of 2020 (P2P), this study investigated the relationships between several high impact curricular and co-curricular educational practices, such as undergraduate research and co-curricular design projects, and postgraduation retention in engineering. Results suggest that participation engineering clubs and professional societies might facilitate post-graduation career commitment in engineering. Moreover, results suggest gaps in opportunities in engineering for women persist even after graduation.
\end{abstract}

\section{Introduction}

Science and technology industry leaders, educators, and policymakers fear that the United States may soon lack, or is currently deficient in, the skilled labor force required to occupy high-paying, high-skilled jobs in the science, technology, engineering, and mathematics (STEM) workforce. ${ }^{{ }^{\prime}}$ The problem, often dubbed the "STEM Crisis", has garnered considerable scholarly, financial, and human resources across the higher education enterprise, as well as an immense amount of federal financial support. The goal is simple: in order to meet national goals related to global competiveness and technological advancement, the United States must produce more graduates in STEM fields to meet industry workforce demands and address growing deficiencies in global competitiveness. $^{2}$

However, according to the Institute of Electrical and Electronics Engineers, the United States educates and graduates enough STEM students to fill vacancies in industry. ${ }^{3}$ Charette argues that the problem is not one of a shortage of talent. Rather the problem lies in attrition from science and technology fields after college graduation. ${ }^{3}$ In the United States over 250,000 undergraduate science, technology, engineering, and mathematics (STEM) degrees are conferred annually. ${ }^{4}$ Still, approximately 277,000 STEM jobs are left vacant each year. ${ }^{3}$ This problem persists, in part, because a substantial number of STEM degree holders work outside of STEM.,

As a result, the colleges and universities that educate future engineers are increasingly asked to consider the impact of higher education attendance far beyond the collegiate experience and degree attainment. This is particularly true in engineering and technology industry, where college graduates are necessary to meet goals related to national challenges and global competitiveness. ${ }^{2,6}$ Indeed, literature, public policy initiatives, and education expenditures have consistently suggested that producing more STEM graduates would address the STEM crisis. 
Given the national impetus for ensuring student success in and beyond college, policies and practices that promote retention and degree attainment, as well as post-graduation outcomes such as job placement and earnings, have received considerable scholarly attention. In 2008, the Association of American Colleges and Universities (AACU) released High Impact Educational Practices: What They Are, Who Has Access to Them, and Why They Matter, detailing a list of curricular, co-curricular, and pedagogical educational practices and experiences that were said to be "widely tested and shown to be beneficial for college students from many backgrounds." " In total, the AACU report listed 10 high impact practices (HIPs), including living-learning communities, collaborative assignments and projects, undergraduate research, service and community based learning, internships, and capstone projects, to name a few. These practices are said to be "high impact" because they facilitate engagement and improve retention in college.

Whereas research on the efficacy of HIPs in promoting retention and degree attainment in college is extensive, few have studied the value of these practices in promoting long-term, postgraduation outcomes, such as professional retention. ${ }^{7}$ Thus, the purpose of this study was to investigate the relationship between participation in several high impact educational practices while in college and engineering students' professional trajectories after graduation in the specific context of the engineering industry, an industry that suffers considerable professional attrition. ${ }^{3}$ This study was guided by the following research question:

Is there a relationship between engineering graduates' participation in high impact educational practices and their post-graduate retention in engineering industry?

\section{Literature Review}

In response to the need to produce more degrees in STEM fields, considerable financial and human resources have been used to establish and maintain educational policies and practices that promote student interest, retention, and graduation in STEM fields broadly, and engineering specifically. ${ }^{2}$ These investments are made, in part, in response to what is known about HIPs, such as research experiences, living-learning communities, service learning, and other curricular and co-curricular activities.

\section{Undergraduate Research}

Scholars studying undergraduate research experiences broadly, and in engineering specifically, have repeatedly suggested that research experiences produce robust outcomes for student participants. For example, in a national survey of 1,135 undergraduate researchers from a wide range of academic fields, Lopatto found undergraduate research experiences promoted students' interests in science careers and further education (e.g., graduate education), as well as critical learning outcomes, such as understanding how scientists and engineers work on real-world problems. ${ }^{8}$ Moreover, extensive research has connected research experiences to post-graduation outcomes, such as academic and professional interests, as well as career choices, suggesting that undergraduate researchers are likely to be retained in their majors and employed in a science related field after graduation. ${ }^{9}$ 
Other researchers have investigated the perceived benefits of undergraduate research in engineering specifically. Zydney, Bennet, Shahid, and Bauer studied engineering alumni and compared the post-graduation perceptions of students who participated in undergraduate research to those who did not. ${ }^{10}$ Undergraduate research participants were more likely to pursue advanced degrees, and reported significantly higher enhancement on academic skills, such as the ability to carry out research and the ability to understand scientific findings. ${ }^{10}$ Perhaps most germane to the present study, Zydney et al. found that undergraduate research participants reported clearer career goals than those who did not participate in undergraduate research, indicating that this particular HIP may be related to post-graduation career outcomes. ${ }^{10}$

\section{Engineering Internships}

Another HIP, internship experiences, wherein students gain direct practical experiences in a professional workplace setting, has been shown to have an impact on students' post-graduate outcomes, such as retention in the field, earnings, and advancement. Internship experiences are particularly beneficial because, when well executed, they involve the development of practical skills, opportunities to apply those skills, and the acquisition of knowledge regarding when and how to apply skills, which are critical to developing expertise. ${ }^{7,11-12}$ Furthermore, internship experiences provide students with professional mentors, supervisors, and coaches who are able to facilitate the development of professional expertise. , $^{71}$

In engineering education literature, research on internship experiences is scarce given that such experiences are not often facilitated by institutional agents or units, rather they are facilitated by agents in industry. Still educational research provides some insights into the benefits of internship experiences, since research experiences (discussed in the previous section) are often conflated with internship experiences broadly. Thus, outcomes related to internship experiences in engineering are similar, if not all the same, to those associated with research experiences. For example, Brooks, Cornelius, Greenfield, and Joseph found that internship experiences might help students clarify their "vocationally relevant self-concept." 13

\section{Service- and Community-Based Learning}

A powerfully efficacious learning opportunity lies in experiences wherein students apply curricular learning to solving real-world problems to meet community needs. Service- and community-based (SCB) learning experiences, often facilitated by institutional agents or community organizations, are designed to create such opportunities. ${ }^{7}$

Research on SCB learning experiences in higher education broadly, and engineering specifically, is extensive. For example, literature suggests SCB learning opportunities in STEM contexts positively impact students' academic motivation, non-academic competencies, and commitment to STEM disciplines. ${ }^{14}$ Other scholars argue that service learning opportunities enhance students' engagement through, and well beyond, the college experience. ${ }^{15}$

Research on SCB learning experiences in engineering suggests similarly robust student outcomes, as well as other engineering-specific learning outcomes mandated by the Accreditation Board of Engineering and Technology (ABET). For example, Ropers-Huilman et 
al. found that SCB learning experiences promote students' ability to (a) design systems to meet real-world needs, (b) perform on multi-disciplinary teams, and (c) communicate their work effectively. ${ }^{16}$ Other studies of service-learning experiences in engineering suggest participants develop a greater sense of social responsibility, and become more aware of the role of engineering in social contexts, including how engineering can benefit people in need. ${ }^{17,18}$

In conclusion, while research on these high-impact educational practices is extensive, most have focused on student outcomes (e.g., college retention, graduation) or post-graduation intentions, rather than post-graduation outcomes. Those studies that explicitly study post-graduation outcomes tend to study these HIPs independently (e.g., research as a predictor of graduate school attendance), rather than as a single part of a broader student experience. The purpose of this study is to fill this gap by studying high-impact practices, along with educational outcomes, to understand post-graduation career trajectories.

\section{Theoretical Framework}

Astin's theory of student involvement provided the theoretical framework for the present study. Astin defined involvement as the amount of physical, emotional, and psychological energy a student devoted to the academic and social collegiate experience. ${ }^{19}$ Highly involved students, for example, are those who engage in various academic tasks (e.g., studying, attending faculty office hours, joining academic societies) and are highly engaged in student organizations.

Three important tenets of Astin's involvement theory were critical in the theoretical framing and methodological choices herein. First, Astin posited that involvement could be measured quantitatively, suggesting that the amount of time a student invested in particular activities was, in part, a measure of the student's involvement. Further, Astin suggested that the learning and development associated with participation in a particular academic or social program is directly related to students' involvement in the program. Finally, involvement theory depicts time as a valuable resource to students, suggesting that activities wherein students must expend the resource of time reflect, to some degree, students' priorities, interests, and long- and short-term goals. Educators, Astin posited, are "competing with other forces in the student's life for a share of that finite time and energy," which are directly related to "the extent to which students can achieve particular developmental goals" (e.g., increasing knowledge and understanding). ${ }^{19}$

Taken collectively, Astin's theory suggests relationships between and among students' behaviors, activities, interests, and goals. ${ }^{19}$ Thus, the present study was informed by two implicit conceptual assumptions that guided the methodological decisions, as well as the interpretation of the findings. The first assumption was that individual student decisions regarding whether or not to participate in a particular co-curricular activity (e.g., research, co-curricular design projects) represents some degree of interest in the activity, as well as the academic domain of the activity (i.e., engineering). The second assumption, which is more directly related to long-term outcomes, was that prolonged participation in particular co-curricular activities represented some degree of commitment to the activity, and thus, to the domain in which the activity exists (i.e., engineering). 
These assumptions were not without theoretical and empirical foundations. Indeed, the literature on student involvement and related constructs, such as student engagement, has consistently made connections between the nature of student involvement and student interests, goals, and short- and long-term, post graduation outcomes. For example, Kuh argued that "engaging in educationally productive activities also builds the foundation of skills and dispositions people need to live a productive, satisfying life after college. ${ }^{, 20}$ Sasone posited that initial task and goal interests and choices often inform students' involvement and engagement decisions. ${ }^{21,22}$ Moreover, Sasone and Thoman suggested that sustaining interest and motivation is often a goal of students" involvement and engagement decisions. ${ }^{22,23}$ Collectively, this suggests that understanding students' participation in particular activities, the extent to which they devote time to particular activities, and the long-term, post-graduation benefits of such temporal commitments, are a potentially fruitful place for scholarly investigation.

\section{Methodology}

\section{Data and Sample}

Data used in this study were collected as a part of a larger, National Science Foundation (NSF) funded study, titled Project to Production: Conditions and Processes for Educating the Engineer of 2020 (P2P). The broad purpose of the P2P study was to investigate curricular, instructional, and organizational practices that facilitate the development of expert engineers. In full, engineering alumni from $30 \mathrm{ABET}$ accredited four-year institutions were surveyed. Each of the 30 institutions included in the sample offered engineering programs in at least two of the following sub-disciplines: bio-medical/bio-, chemical, civil, electrical, general, industrial, or mechanical engineering.

The engineering alumni included in the sample consisted of graduates who were conferred degrees in one or more of the engineering disciplines mentioned above following the 2005-2006 academic year. Data collection, which occurred in 2009, marked approximately three years since the graduation date of the alumni included in the sample. Measuring post-graduation outcomes of engineering alumni three years after graduation is consistent with other literature on engineering students' intentions and goals after graduation. ${ }^{24}$

In full, 7,307 engineering alumni were invited to participate in the P2P study, and 1,403 alumni returned surveys to be included in the sample, yielding a response rate of approximately $19 \%$. However, since some participants were missing data for the dependent variable, the effective sample size was 1,310 engineering alumni. This is explained further in later sections.

Descriptive statistics were calculated to ascertain the representativeness of the sample. Table 1 presents the results of the descriptive statistics and NSF published statistics for engineering degrees conferred in 2006, as well as indicators of the approximate representativeness of the sample. Results indicated that the effective sample was not representative of national statistics for engineering graduates as published by the American Society for Engineering Education (ASEE). 
Table 1

Descriptive Statistics for Sample and National Comparison

\begin{tabular}{|c|c|c|}
\hline & $\begin{array}{c}\text { ASEE National Statistics } \\
(\%)\end{array}$ & $\begin{array}{c}\text { P2P Study Sample } \\
(\mathrm{N}=1,310) \\
\mathrm{n}(\%)\end{array}$ \\
\hline \multicolumn{3}{|l|}{ Control Variables } \\
\hline \multicolumn{3}{|l|}{ Gender } \\
\hline Female & $19.3 \%$ & $335(25.6 \%)$ \\
\hline Male & $80.7 \%$ & $975(74.4 \%)$ \\
\hline \multicolumn{3}{|l|}{ Race/Ethnicity* } \\
\hline African American & $4.7 \%$ & $35(2.7 \%)$ \\
\hline Asian/Pac Islander & $12.7 \%$ & $85(6.5 \%)$ \\
\hline Hispanic/Latino & $6.7 \%$ & $58(4.4)$ \\
\hline Am. Indian/Alaskan & $0.5 \%$ & $2(0.2 \%)$ \\
\hline Other & $7.1 \%$ & $59(4.5 \%)$ \\
\hline Foreign & $6.9 \%$ & $31(2.4 \%)$ \\
\hline Caucasian & $61.3 \%$ & $989(75.5 \%)$ \\
\hline Multiracial & - & $51(3.9 \%)$ \\
\hline \multicolumn{3}{|l|}{ Academic Discipline } \\
\hline Biomedical & $5.7 \%$ & $61(4.7 \%)$ \\
\hline Chemical & 8.5 & $158(12.1 \%)$ \\
\hline Civil & 17.1 & $219(16.7 \%)$ \\
\hline Electrical & 28.0 & $295(22.5 \%)$ \\
\hline Industrial & 7.2 & $97(7.4 \%)$ \\
\hline Mechanical & 31.2 & $418(31.9 \%)$ \\
\hline General Engineering & $5.7 \%$ & $34(2.6 \%)$ \\
\hline Other & - & $28(2.1 \%)$ \\
\hline
\end{tabular}

Notes: *Categories of race/ethnicity in this study did not necessarily match the categories provided by the American Society of Engineering Education

\section{Measures}

The outcome under investigation in this study was engineering alumni retention in their respective engineering sub-discipline after graduation. Engineering graduates reported the degree to which their professional work was related to the field for which they earned their undergraduate engineering degrees. Alumni responded that their current work was directly related, somewhat related, or not related to their undergraduate academic major(s). However, the outcome of interest was dichotomized in the interest of comparing all outcomes to the optimal outcome (i.e., employment in a job that is directly related to one's engineering major). This is explained in detail in later sections.

Explanatory variables consisted of independent variables and control variables. Control variables included students' academic major grade point average (GPA). The major GPA was included to 
account for the potential role that engineering competence, as reflected by students' GPA in their respective academic major, may have played in their decision to pursue, or leave, engineering professionally. Additionally, given what is known from literature about demographic differences in academic and professional outcomes for engineers specifically, as well as the potential for selection bias for several HIPs, demographic characteristics were also controlled for, including gender and race/ethnicity.

The independent variables under investigation included students' participation in several high impact curricular and co-curricular practices in college (HIPs). Co-curricular HIPs included in this study included the number of months alumni spent in (a) undergraduate research, (b) engineering internships, (c) study abroad, (d) humanitarian engineering projects, and (e) student design projects. An additional covariate investigated in this study was the degree to which alumni were engaged in engineering clubs and professional organizations during their undergraduate careers.

Each covariate in this study was used to operationalize a particular HIP in engineering specifically. For example, alumni responses regarding the degree to which they were involved in engineering clubs and professional societies was used to operationalize the Kuh's conception of "common intellectual experiences."7 Alumni responses regarding their participation in study abroad experiences were used to operationalize the Kuh's "diversity and global learning" practice. ${ }^{7}$ Finally, co-curricular engineering design projects were used to operationalize Kuh's definition of collaborative projects. ${ }^{7}$ Table 2 presents descriptive statistics of participation rates (i.e., how many participated), as well as central tendency measures for students' length of participation in months in each practice.

\section{Analytical Procedure}

Several steps were taken to prepare data for analysis. First, data were analyzed to determine both the amount and mechanism of missing data. Alumni who were either missing data for the dependent variable, or were missing more data for more than $20 \%$ of the survey items, were removed from the analysis. In total, 93 participants, or about $7 \%$ of the sample, were removed. Additionally, literature suggests that the amount and mechanism of missing data should guide methodological choices regarding how missing data are handled. ${ }^{25}$ Since missing data were determined to be missing at random, expectation maximization (EM) was used to impute missing data. Various statistical packages utilize varying EM algorithms to impute missing data. In general, EM algorithms are "iterative procedures that produce maximum-likelihood estimates.",26 In the present study, the EM algorithm provided by the Statistical Package for the Social Sciences (SPSS) (v. 18) was used to impute missing data. 
Table 2

Descriptive Statistics and Central Tendency for Item Responses $(N=1,310)$

\begin{tabular}{|c|c|c|c|c|c|}
\hline & $\%$ Participated & Mean & Std Dev. & Min & Max \\
\hline $\begin{array}{l}\text { Dependent Variable } \\
\text { Dichotomized: Career } \\
\text { Directly Related to their } \\
\text { major. }\end{array}$ & $639(48.78 \%)$ & - & - & - & - \\
\hline Job is Directly Related: & $639(48.8 \%)$ & - & - & - & - \\
\hline Job is Somewhat Related: & $572(43.7 \%)$ & - & - & - & - \\
\hline Job is Not Related: & $99(7.6 \%)$ & - & - & - & - \\
\hline \multicolumn{6}{|l|}{ Covariates } \\
\hline $\begin{array}{c}\text { Undergraduate } \\
\text { Research }\end{array}$ & $840(64.1 \%)$ & 6.40 & 8.28 & 0 & 60 \\
\hline Internship & $889(67.9 \%)$ & 5.65 & 7.19 & 0 & 60 \\
\hline \multicolumn{6}{|l|}{ Experiences } \\
\hline Study Abroad & $201(15.3 \%)$ & 0.59 & 2.79 & 0 & 48 \\
\hline Service Learning & $927(70.8 \%)$ & 9.4 & 13.93 & 0 & 90 \\
\hline Design Project & $632(48.2 \%)$ & 3.56 & 6.38 & 0 & 60 \\
\hline $\begin{array}{l}\text { Engineering Club or } \\
\text { Professional }\end{array}$ & $909(69.4 \%)$ & 2.32 & 1.21 & 1 & 5 \\
\hline \multicolumn{6}{|l|}{ Society* } \\
\hline Not Active & $401(30.6 \%)$ & & & & \\
\hline Slightly Active & $403(30.8 \%)$ & & & & \\
\hline Moderately & $287(21.9 \%)$ & & & & \\
\hline \multicolumn{6}{|l|}{ Active } \\
\hline Highly Active & $119(9.1 \%)$ & & & & \\
\hline Extremely Active & $100(7.6 \%)$ & & & & \\
\hline
\end{tabular}

In Model 1 and Model 2, the outcome of interest was retention in engineering professionally after graduation, which was coded dichotomously: 1 for alumni whose work was directly related to their undergraduate engineering discipline, and 0 otherwise. Since the outcome of interest was dichotomous, two binary logistic regression models (i.e., logit models) were estimated in order to understand relationships between the outcome of interest and the explanatory variables.

In logit models the dependent variable represents the log of the odds ratio, which is continuous. That is, the probability of an event, $p$, can be can be represented in terms of an odds ratio. If $p$ is the probability that an engineering alumni will have a job that is directly related to their undergraduate major, Equation 1 below gives the odds:

$$
\frac{p}{1-p}
$$


Thus, Equation 2 expresses the logit model, which is a linear combination of explanatory variables. That is, a unit change in an explanatory variable is related to a change in the log-odds of the outcome:

$$
\ln \left(\frac{p}{1-p}\right)=\alpha+\beta_{1} x_{1}+\cdots+\beta_{i} x_{i}
$$

However, since log-odds are not easily interpreted, raw coefficients are often transformed such that the combination of odds-ratios presented in Equation 3 represents the change in the odds of a particular outcome:

$$
\frac{p}{1-p}=e^{\alpha}+e^{\beta_{1}} x_{1}+\cdots+e^{\beta_{i}} x_{i}
$$

Odds-ratios greater than one represent an increase in the odds of an outcome relative to the baseline outcome. Conversely, odd-ratios less than one represent a decrease in the likelihood of an outcome relative to the baseline outcome.

Finally, several indicators of model fit were used to assess the four models. Likelihood ratio tests were used to compare nested models, and statistics, such as the McFadden's R-squared statistic, were observed to assess model fit. Each of these is detailed in the results section below.

\section{Limitations}

There were several limitations in this study. First, the relationship between alumni professional work and their undergraduate major (i.e., directly related, somewhat related, and not related) was the result of individual perceptions of their work in relation to their undergraduate major rather than a rigorously applied definition of the researcher. Given the subjective nature of alumni responses, it is possible that individual responses do not reflect a universally accepted notion of what it means to work in a position that is directly, somewhat, or not related to mechanical engineering, for example.

Second, while the use of three years post-graduation positions are consistent with other engineering education literature on post-graduation outcomes, this paper does not, and cannot, comment on alumni commitments to the field of engineering, or any pattern of movement during, or after, the three year period between graduation and survey administration. It is possible that some alumni left the field and intend to return. It is possible that some alumni have simply advanced to positions that require fewer engineering skills, and are thus perceived to be less related (i.e., somewhat or not related) to engineering (e.g., managerial positions). Again, responses were based on individual perceptions of relationships between an alumnus's professional work and their engineering degree.

While some attempts were made to account for outside influences, such as institutional difference and engineering sub-disciplinary difference, this does not account for all potential factors that may influence career outcomes. The framework employed in this study, wherein collegiate experiences are related to students' professional commitments and thus their professional outcomes, is not a framework typically employed to study the relationship between collegiate experiences and post-graduation outcomes. Other theoretical frameworks, such Social 
Cognitive Career Theory (SCCT), consider factors that may inform career decision-making and choices, such as self-efficacy beliefs and outcome expectations, that go beyond the scope of the present study. ${ }^{27}$ Still, the analysis in this paper, which was designed to explore relationships between undergraduate co-curricular experiences and post-graduation retention, is useful in that it provides some evidence for the efficacy of particular high impact practices for enhancing professional advancement in industry.

Finally, the survey used in this study ascertained student involvement in particular practices, as well as the length of time (i.e., in months) or degree of involvement (e.g., not involved, moderately involved, extremely involved). The survey did not ascertain information about the nature of student involvement. Simply put, not all HIPs are created equally, and some studies suggest that different types of engagement in particular HIPs may inform varying outcomes. For example, Strayhorn found that undergraduate researchers who were involved in data collection and analysis had higher degree aspirations than those who only wrote literature reviews. ${ }^{28}$ Thus, understanding the varying nature of student involvement in particular HIPs is a critical area for future research.

\section{Results}

The two models (i.e. Models 1 and 2) offer various perspectives regarding how the results might be interpreted. Thus, the results section is divided to discuss both models.

\section{Model 1 and Model 2: Dichotomous Outcome}

Model 1 and Model 2 involved investigating the relationships between the dichotomized dependent variable and the independent variables of interest. Specifically, the dependent variable was coded 1 for alumni who worked in jobs that were directly related to their undergraduate major and 0 otherwise. This was done with the assumption that directly related work is the optimal career outcome and that all other outcomes should be measured against the optimal outcome. Model 1 differed from Model 2 in that in Model 1, the explanatory variables were dichotomized such that students who participated in a particular high impact practice (e.g., research, internships, etc.) for any length of time or with any degree of involvement were coded as 1 for that respective high impact practice. Conversely, in Model 2, the explanatory variables were continuous, representing the length of time, in months, that alumni participated in each high impact practice during their undergraduate career. Full results for Model 1 are presented in Table 3 below, and full results for Model 2 are presented in Table 4.

Model 1 (Table 3) was estimated using a stepwise approach (Table 3 and Table 4). In Model 1a, dichotomous career outcome was estimated using only demographic (i.e., REM status and sex) and achievement (i.e., engineering program grade point average at college graduation) explanatory variables. Results indicated that both racial/ethnic minority status and sex were statistically significant predictors of post-graduation persistence in careers that are directly related to alumni baccalaureate degrees in engineering. Specifically, REM status was associated with a $24.2 \%$ (odds ratio $=0.758$ ) reduction in the odds that an alumnus would hold a job that is directly related to their engineering degree. Moreover, women were $33 \%$ less likely to be 
employed in jobs that are directly related to their undergraduate engineering major (odds ratios $=$ $0.670)$.

Results from Model 1b, wherein only dichotomous explanatory variables related to each high impact practice (e.g., research experiences, internships) were included, indicated that participation in co-curricular engineering design projects, as well as participation in engineeringrelated clubs and professional societies, were statistically significant predictors of postgraduation professional retention in engineering. Interestingly, though high impact practices are said to be beneficial to students from many backgrounds, model fit statistics indicated that the Akaike Information Criterion (AIC) for Model 1a $(1,801.857)$ was smaller than that of Model $1 \mathrm{~b}$ (1,814.666), suggesting that the model with only demographic variables was a better fit than the model with only high impact practice variables.

The Full Model 1 (Table 3), wherein all demographic and achievement variables, as well as the covariates related to high impact educational practices, were included, offered fairly consistent results with Model 1a and 1b. That is, sex and participation in engineering clubs emerged as statistically significant predictors of post-graduation persistence in engineering. Like Models 1a and $1 \mathrm{~b}$, participation in engineering clubs was associated with an increase in the odds of persistence (odds ratio $=1.321$ ), while women were less still less likely than men to be employed in a job that was directly related to their major after accounting for participation in high impact practices (odds ratio $=0.660)$.

Model fit statistics for the Full Model 1 indicated that the inclusion of both demographic, achievement, and high impact practice related covariates resulted in a statistically better model than the null (i.e., intercept only) model $\left(\chi^{2}(9, N=1,310)=34.29, p<0.001\right)$, as well as Models 1a $\left(\chi^{2}(6, N=1,310)=13.57, p=0.035\right)$ and Model $1 \mathrm{~b}\left(\chi^{2}(3, N=1,310)=\right.$ 20.38, $p<0.001)$.

\begin{tabular}{|c|c|c|c|}
\hline \multicolumn{4}{|c|}{$\begin{array}{l}\text { Table } 3 \\
\text { Model } 1 \text { Estimating Dichotomized Persistence in Industry using Dichotomous Predictors }{ }^{\wedge}\end{array}$} \\
\hline & Odds Ratios & Odds Ratios & Odds Ratios \\
\hline & (Standard Errors) & (Standard Errors) & (Standard Errors) \\
\hline High Impact Practices^^ & Model 1a & Model 1b & Full Model \\
\hline Undergraduate Research & - & $0.859(0.103)$ & $0.875(0.108)$ \\
\hline Internship Experiences & - & $0.847(0.104$ & $0.855(0.106)$ \\
\hline Study Abroad & - & $0.973(0.155)$ & $1.031(0.166)$ \\
\hline Engineering Design Project & - & $1.286(0.152)^{*}$ & $1.262(0.151)$ \\
\hline Service Learning & - & $1.090(0.140)$ & $1.131(0.146)$ \\
\hline Engineering Club/Society & - & $1.341(0.167)^{*}$ & $1.321(0.168)^{*}$ \\
\hline Racial/Ethnic Minority & $0.758(0.100)^{*}$ & - & $0.771(0.104)$ \\
\hline Female & $0.670(0.087)^{* *}$ & - & $0.660(0.088)^{* *}$ \\
\hline GPA (at graduation) & $1.134(0.074)$ & - & $1.124(0.075)$ \\
\hline Observations & 1,310 & 1,310 & 1,310 \\
\hline Null Log Likelihood & -907.632 & -907.632 & -907.632 \\
\hline Final Log Likelihood & -896.929 & -900.333 & -890.144 \\
\hline Pseudo $\mathrm{R}^{2}$ & 0.012 & 0.008 & 0.019 \\
\hline
\end{tabular}


Like Model 1, Model 2 (Table 4) involved investigating the dichotomized dependent variable. Since Model 2a used identical demographic and achievement variables as Model 1a, Models 1a and $2 \mathrm{a}$ are identical. However, Model $2 \mathrm{~b}$ differed from Model $1 \mathrm{~b}$ in that Model $2 \mathrm{~b}$ investigated relationships using continuous covariates. In Model 2, explanatory variables related to alumni participation in high impact practices during their undergraduate career were continuous, indicated the length in months that each alumnus reported participating in each practice.

In Model 2b, wherein continuous explanatory variables were used to estimate engineering career outcomes, several variables emerged as statistically significant predictors. Like Model 1b, cocurricular engineering design projects (odds ratio $=1.027$ ) and participation in engineering clubs and professional societies were related to increased odds of employment in jobs that are directly related to an alumnus' respective engineering major. However, the continuous nature of the explanatory variables offered additional interpretation. That is, prolonged participation in cocurricular engineering design project was associated with a $2.7 \%$ increase per month of participation in the odds of directly related employment, holding all other explanatory variables constant. Moreover, students who were moderately active in engineering clubs and professional societies were more likely to hold jobs that were directly related to their major than all other levels of activity in engineering organizations (see Table 4).

Like the Full Model 1, the Full Model 2 included all explanatory variables. While several statistically significant explanatory variables emerged in the Full Model, Model 2 was similar to Model 1 in that women were still significantly less likely to be employed in jobs that are directly related to their majors after accounting for the length of participation in high impact practices (odds ratio $=0.639$ ), holding all other predictors constant.

Model fit statistics provided support for the inclusion of demographic, achievement, and high impact educational practice variables in the Full Model 2. Likelihood ratio tests indicated that the Full Model 2 provided statistically significant improvements to $\operatorname{Model} 2 \mathrm{a}\left(\chi^{2}(9, N=1,310)=\right.$ $26.37, p=0.002)$ and Model $2 b\left(\left(\chi^{2}(3, N=1,310)=20.74, p<0.001\right)\right.$. Moreover, the Full Model was a statistically better fit than the intercept only model $\left(\chi^{2}(12, N=1,310)=\right.$ $44.25, p=0.002)$.

\section{Discussion}

Recall that the purpose of this study was to investigate the relationship between engineering graduates' participation in high impact educational practices while in college and their postgraduation professional work. Results from the present study suggest that, while some practices, such as engineering professional clubs and societies were significant predictors of whether or not a graduate would hold a job that is directly related to their engineering major, other commonly elevated high impact practices, such as research experiences, were not significantly related to post-graduation engineering employment, as measured in the present study. Moreover, gender disparities in post-graduation outcomes persisted, even after accounting for participation in high impact practices. 


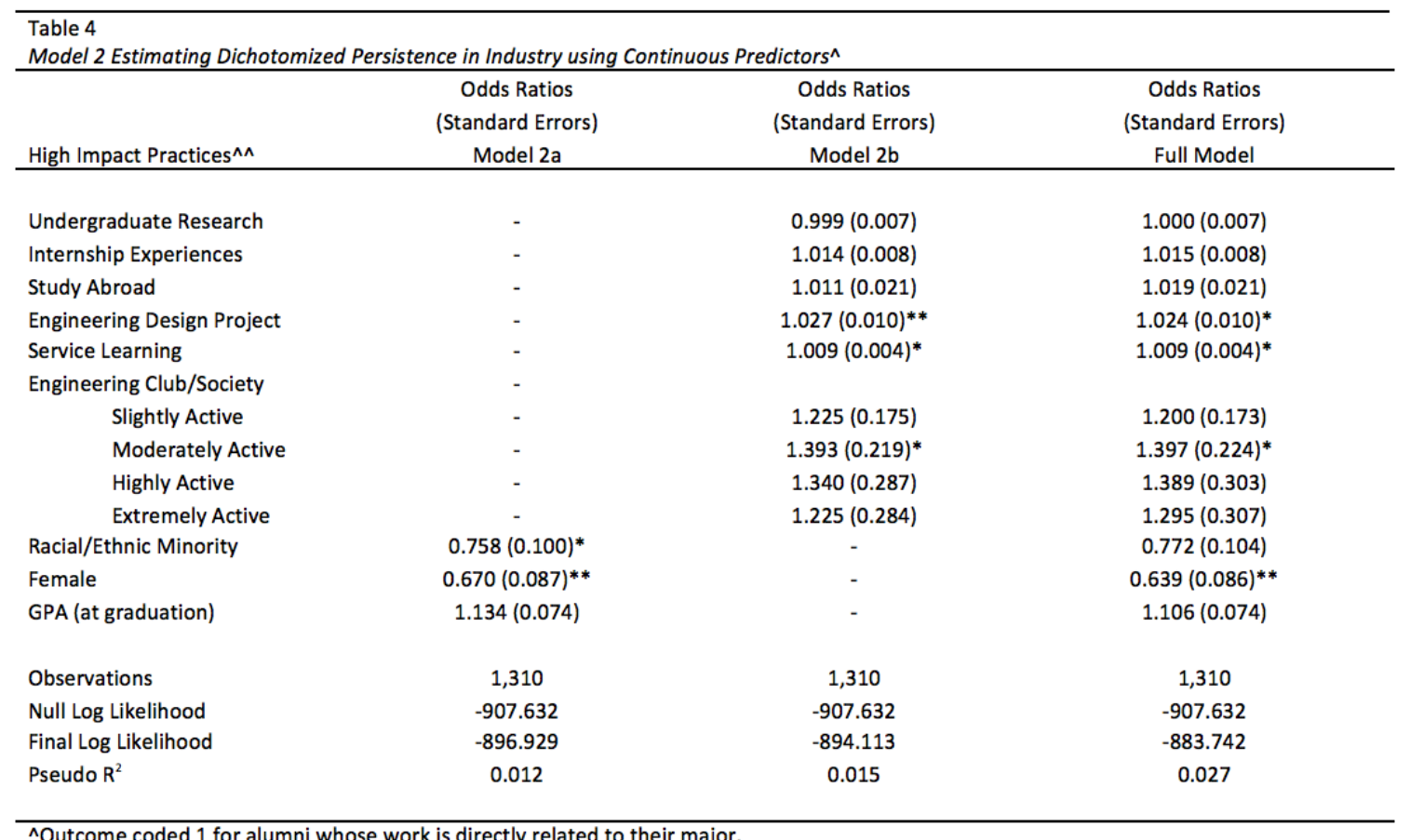

^ Outcome coded 1 for alumni whose work is directly related to their major.

$\wedge^{\wedge}$ Predictors left continuous for number of months participating each activity or degree of involvement.

Degree of involvement coded 1 for no involvement and 5 for Extremely Active.

${ }^{* * *} p<.001, * * p<0.01, * p<0.05$

The methodological decisions in this study, as well as the interpretations of the study's results, were informed by two assumptions. The first assumption was that decisions regarding whether or not to participate in particular co-curricular activities represent some degree of interest in the activity, as well as the academic domain of the activity. The second assumption was that prolonged participation in particular co-curricular activities represent some degree of commitment to the activity, and thus, to the domain in which the activity exists (i.e., engineering).

Given that research has consistently found that engineering degree attainment alone does not imply an intent to pursue engineering professionally these assumptions are critical to framing and interpreting the findings of this study. ${ }^{29}$ If, as the guiding theoretical framework suggests, task selection and engagement are indicative of some degree of interest in, motivation for, and commitment to a particular task, then selection of high impact practices in engineering, involvement and engagement in those practices as a student, and degree conferral in engineering, implies some degree of interest in, motivation for, and commitment to engineering above and beyond degree conferral alone. ${ }^{21-23}$

If this is true, then there is a straightforward explanation for the fact that engineering clubs and professional societies, as well as co-curricular engineering design projects, in particular emerged as a statistically significant predictors of post-graduation employment in directly related engineering jobs. Research on engineering career decision-making has suggested that, given the difficulty of transferring engineering credits to other academic disciplines and the lengthy timeto-degree of engineering fields, some students complete engineering degree while wavering, or 
altogether abandoning, professional engineering pursuits. ${ }^{6,29}$ However, the nature of co-curricular engineering design projects and engineering clubs and professional societies suggest a commitment to engineering above and beyond simply completing academic requirements for degree conferral.

Additionally, that disciplinary specific (i.e., engineering-related) clubs and organizations were statistically significant predictors of career outcomes was not surprising if it is assumed that participating in a professional organization represents some degree of professional interest and commitment. Moreover, that some co-curricular practices emerged as statistically significant predictors of career outcomes only when the length of participation was considered is consistent with research on engineering career decision-making, student involvement literature, and scholarship on student engagement. ${ }^{7,21,29}$ That is, if it is assumed that lengthier participation is related to greater interest in, and commitment to, the activity specifically, and the domain of the activity broadly, then Astin's theorized relationship between time expenditures and interests, goals, and outcomes holds even for engineering, where students often complete degrees with little or no intention of pursuing engineering professionally. ${ }^{19,29}$

The two assumptions mentioned above also underscore the need for research on students' pathways from engineering degrees to, and through, industry. Extant literature has suggested that in order to address gender disparities in the engineering workforce, institutions of higher education must facilitate the success of more women in engineering, as measured by the number of women who earn engineering degrees. ${ }^{30}$ Results from this study indicate that, taken alone, the odds that women will hold jobs that are directly related to their engineering degree are significantly lower than their male counterparts. At least for the women in this study, the problem was not degree attainment. Indeed, their inclusion in the study implied degree attainment had already occurred.

Moreover, even after accounting for their participation in high-impact educational practices in engineering, which is assumed to represent some degree of interest and commitment, the difference in odds-ratios between men and women remained relatively unchanged across the models. Findings in this study suggested that male and female engineering students may not share the benefits of participating in high impact educational practices in engineering equally, refuting the claims in Kuh's report. ${ }^{7}$

This reality is startling considering that much of the literature on women in engineering assumes that degree attainment will cure gender disparities in industry. This underscores a potentially rich place for future research. For example, future research might investigate students' reasons for engaging in high impact educational practices, and whether sex-based patterns emerge. Moreover, future research might investigate students' experiences in high impact educational practices and whether sex-based differences might explain the differences post-graduation outcomes. Finally, since it is not clear, based on the results of this study, whether women's postgraduation pathways out of engineering begin in college or in industry, more must be known about why women fail to enter, choose to leave, or are pushed out of, the industry for which they are academically and professionally trained. Focusing future research and interventions on women's pathways into industry may go a long way to solving gender disparities in engineering industry. 


\section{Bibliography}

[1] Craig, E., Thomas, E. C., Hou, C., \& Mathur, S. (2011). No shortage of talent: How the global market is producing the STEM skills needed for growth. Accenture Institute for High Performance. Retrieved from: www.accenture.com/sitecollectiondocuments/accenture-noshortage-of-talent.pdf.

[2] White House Office of Science and Technology Policy. (2014). Preparing Americans with $21^{\text {st }}$ century skills: Science, technology, engineering, and mathematics (STEM) education in the 2015 budget. Retrieved from: https://www.whitehouse.gov/sites/default/files/microsites/ostp/fy_2015_stem_ed.pdf.

[3] Charette, R. N. (2013). The STEM crisis is a myth. IEEE Spectrum. Retrieved from: http://spectrum.ieee.org/at-work/education/the-stem-crisis-is-a-myth.

[4] U.S. Department of Education. (2014). Fast facts. Washington, D. C.: National Center for Educational Statistics. Retrieved from: https://nces.ed.gov/programs/digest/d13/tables/dt13_318.20.asp.

[5] Bureau of Labor Statistics. (2015). Monthly labor review. Retrieved from: https://www.bls.gov/opub/mlr/2015/article/stem-crisis-or-stem-surplus-yes-and-yes.htm.

[6] Chen, X., \& Soldner, M. (2013). STEM attrition: College students' paths into and out of STEM fields (NCES 2014 - 001). Washington, D.C.: U.S. Department of Education, National Center for Educational Statistics. Retrieved from: http://nces.ed.gov/pubs2014/2014001rev.pdf.

[7] Kuh, G. D. (2008). High impact educational practices: What they are, who has access to them, and why they matter. Association of American Colleges and Universities. Retrieved from: http://provost.tufts.edu/celt/files/High-Impact-Ed-Practices1.pdf.

[8] Lopatto, D. (2004). Survey of undergraduate research experiences (SURE): First findings. Cell Biology Education, 3(4), 270 - 277.

[9] Odera, E., Lamm, A. J., Odera, L. C., Duryea, M., \& Davis, J. (2015). Understanding how research experiences foster undergraduate research skill development and influence STEM career choice. NACTA Journal, 59(3), 180 - 188.

[10] Zydney, A. L., Bennett, J. S., Shahid, A., \& Bauer, K. W. (2002). Impact of undergraduate research experience in engineering. Journal of Engineering Education, 91(2), 151-157.

[11] Litzinger, T. A., Lattuca, L. R., \& Hadgradt, R. G. (2011). Engineering education and the development of expertise. Journal of Engineering Education, 100(1), 123 - 150. 
[12] Ambrose, S. A., Bridges, M. W., DiPietro, M. Lovett, M. C., \& Norman, M. K. (2010). How learning works: Seven research-based principles for smart teaching. San Francisco, CA: JosseyBass.

[13] Brooks, L., Cornelius, A., Greenfield, E., \& Joseph, R. (1995). The relation of career-related work or internship experiences to the career development of college seniors. Journal of Vocational Behavior, 46(3), $332-349$.

[14] Sevier, C., Chyung, S. Y., Callahan, J., Schrader, C. B. (2012). What value does service learning have on introductory engineering students' motivation and ABET program outcomes? Journal of STEM Education: Innovations \& Research, 13(4), 55 - 70.

[15] Felton, P. \& Clayton, P. H. (2011). Service-learning. New Directions in Teaching and Learning, 2011(128), $75-84$.

[16] Ropers-Huilman, B.. Carwile, L., \& Lima, M. (2005). Service-learning in engineering: A valuable pedagogy for meeting learning objectives. European Journal of Engineering Education, $30(2), 155-165$.

[17] Bielefeldt, A. R. \& Canney, N. (2014). Impacts of service-learning on the professional social responsibility attitudes of engineering students. International Journal for Service Learning in Engineering, 9(2), 47 - 63.

[18] Dukhan, N., Schumack, M. R., \& Daniels, J. J. (2008). Implementation of service-learning in engineering and its impact on student' attitudes and identity. European Journal of Engineering Education, 33(1), $21-31$.

[19] Astin, A. (1999). Student involvement: A developmental theory of higher education. Journal of College Student Development, 40(5), 518 - 529.

[20] Kuh, G. D. (2009). The national survey of student engagement: Conceptual and empirical foundations. New Directions for Institutional Research, 2009(141), 5- 20.

[21] Sasone, C. (2009). What's interest got to do with it?: Potential trade-offs in the selfregulation of motivation. In J. P. Forgas, R. Baumiester, \& D. Tice (Eds.), Psychology of selfregulation: Cognitive, affective, and motivational processes (pp. 35 - 51). New York, NY: Psychology Press.

[22] Renninger, K. A. \& Hidi, S. (2011). Revisiting the conceptualization, measurement, and generation of interest. Educational Psychologist, 46(3), 168 - 184.

[23] Sasone, C. \& Thoman D. B. (2005). Interest as the missing motivator in self-regulation. European Psychologist, 10, $175-186$. 
[24] Eris, O., Chachra, D., Chen, H. L., Sheppard, S., Ludlow, L., Rosca, C., Bailey, T., \& Toye, G. (2010). Outcomes of a longitudinal administration of the persistence in engineering survey. Journal of Engineering Education, 99(4), 371 - 395.

[25] Cohen, J \& Cohen, P. (1983). Applied multiple regression/correlation analysis for the behavioral sciences (2nd ed.). Hillsdale, NJ: Erlbaum.

[26] Graham, J. W. (2009). Missing data analysis: Making it work in the real world. Annual Review of Psychology, 60(1), 549 - 576.

[27] Lent, R. W., Brown, S. D., \& Hackett, G. (2000). Contextual supports and barriers to career choice: A Social cognitive analysis. Journal of Counseling Psychology, 47(1), 36 - 49.

[28] Strayhorn, T.L. (2010). Undergraduate research participation and STEM graduate degree aspirations among students of color. New Directions for Institutional Research, 148, 85 - 93.

[29] Lichtenstein, G., Loshbaugh, H. G., Claar, B., Chen, H. L., Jackson, K., \& Sheppard, S. D. (2009). An engineering major does not an engineer make: Career decision making among undergraduate engineers. Journal of Engineering Education, 98(3), 227 - 234.

[30] Stewart, A. J., Malley, J. E., \& Lavaque-Manty, D. (2007). In A. J. Stewart, J. E. Malley, \& D. Lavaque-Manty (Eds.), Transforming science and engineering: Advancing academic women $(3-20)$. Ann Arbor, MI: University of Michigan Press.

\section{Funding acknowledgement:}

This study was made possible by a grant from the National Science Foundation (NSF EEC0550608). The opinions expressed here do not reflect the opinions or policies of NSF, and no official endorsement should be inferred.

\section{Acknowledgement:}

The author wishes to acknowledge the contributions of the members of the research team who participated in various stages of the development of the design, instruments, and databases for this project: Lisa R. Lattuca, Patrick T. Terenzini, Gul Kremer, and Thomas Litzinger, Coprincipal investigators; (then) post-doctoral researchers Betty J. Harper and Alexander Yin; and (then) graduate research assistants David Knight, India McHale, Daniel Merson, David C. Perez II, and Hyun Kyoung Ro. Travis York also served as graduate student researcher on the project team. 